\title{
Mechanisms of Change in Dialectical Behaviour Therapy and Cognitive Behaviour Therapy for Borderline Personality Disorder: A Critical Review of the Literature
}

[Mechanisms of Change in DBT and CBT for BPD]

Rudge, Susie ${ }^{1}$, Feigenbaum, Janet ${ }^{1}{ }^{2}$, Fonagy, Peter $^{1}$

1 Research Department of Clinical, Educational and Health Psychology, University College London

2 North East London NHS Foundation Trust

Address for correspondence: Dr Susie Rudge, c/o Dr Janet Feigenbaum, Research Department of Clinical, Educational, and Health Psychology, University College London, Gower Street, London WC1E 6BT

Email: susie.webb.10@ucl.ac.uk / susie.rudge@hotmail.co.uk

Declarations of interest: Susie Rudge and Peter Fonagy - None. Janet Feigenbaum is an international senior trainer in DBT with British Isles DBT, and Chairman of the Board of Accreditation for the Society for DBT UK. 


\title{
Mechanisms of Change in Dialectical Behaviour Therapy and Cognitive Behaviour Therapy for Borderline Personality Disorder: A Critical Review of the Literature
}

\begin{abstract}
Background: Little is known about the 'active ingredients' of psychological therapy for Borderline Personality Disorder (BPD) despite a growing evidence base documenting its clinical effectiveness. This information can be used by clinicians to inform service planning and care pathways.
\end{abstract}

Aims: To review published empirical research investigating the potential mechanisms underlying therapeutic change in Dialectical Behaviour Therapy (DBT) and Cognitive Behaviour Therapy (CBT) for BPD.

Method: A thorough search of the PsychInfo, CINAHL Plus, PubMed, MEDLINE and EMBASE databases revealed research into potential mechanisms of change.

Results: A total of 52 abstracts were reviewed. After a full text screen of the most relevant studies, 14 met inclusion criteria. Twelve examined DBT and two CBT. Mechanisms of change identified broadly fell into three categories: emotion regulation/self-control, skills use and therapeutic alliance/investment in treatment. Outcomes measured included general mental health diagnoses (e.g. anxiety, depression) and BPD-specific symptoms (e.g. selfharm/suicidality, impulsivity, substance misuse, anger).

Conclusion: Further empirically-robust research is required to test hypotheses about the influence of the proposed mechanisms on therapeutic change in psychological therapies for BPD.

Keywords: borderline personality disorder, CBT, DBT, outcomes, therapeutic change

Declaration of interests: Omitted here for purpose of blinded review 


\section{Background}

Borderline Personality Disorder (BPD) is arguably the most common subtype of Personality Disorder seen by services (Coid et al, 2006; de Ruiter \& Greeven, 2000) and has been extensively studied due to its association with suicide, self-harm, violence, and substance misuse (American Psychiatric Association, 2013). Symptoms of BPD result in high levels of service usage (Bender et al., 2001; Comtois et al., 2003) and high mortality rates (American Psychiatric Association, 2001).

Several characteristics of the disorder (e.g. impulsivity, recurrent suicidal behaviour) unfortunately lend themselves to early disengagement from treatment and difficulty committing to and engaging with the therapeutic process. Additionally, BPD is characterised by difficulties in establishing trusting and collaborative interpersonal relationships and, "frantic efforts to avoid real or imagined abandonment" (American Psychiatric Association, 2013), which naturally extend to difficulties in the therapeutic relationship. Indeed, a recent qualitative study confirmed patients' reluctance to be open and honest with their therapist because of fears of rejection and abandonment (Morris et al., 2014). Owing to the stigma associated with BPD, clinicians may find it difficult to communicate the diagnosis in a patient-centred manner (Sulzer et al., 2015), further exacerbating problematic therapist-patient relationships.

Although research has sought to identify effective therapeutic treatments for the condition, the majority of BPD research to date focuses on outcome data with relatively few studies identifying reasons why therapies are successful, and what the specific processes through which improvements occur might be (Lynch et al., 2006). Linehan (2000) notes the need to identify 'active' components of psychological therapy so that those aspects can be emphasised when striving for the most effective treatment. Clarkin and Levy (2006) highlight the difference between the vast number of outcome studies and the relatively few studies of mechanisms of change clarifying that, "the question of the mechanisms of change in psychotherapy seeks to learn how a particular therapy works, not what is the outcome of the 
treatment per se". Elliott (2010) refers to this research as 'change process research' describing it as, "a necessary complement to randomised clinical trials and other forms of efficacy research". Even in the most rigorously researched psychotherapeutic interventions, researchers lack insight into the mechanisms through which these treatments result in successful outcomes and future investigations should strive towards evidencing this as the next step in psychotherapy research (Kazdin, 2007). Identifying specific mechanisms through which symptoms improve with treatment has vast implications for the future of psychological therapy for BPD. Pre-assessment, this data could allow clinicians to predict which patients are more likely to do well with which treatment. As well as informing care pathways, this information could assist in the planning and formation of new services.

Current therapies for BPD include Dialectical Behaviour Therapy (DBT; Linehan et al., 2006a), Cognitive Behaviour Therapy (CBT; Beck et al., 2004), Mentalization Based Therapy (MBT; Bateman \& Fonagy, 2008; Bateman \& Fonagy, 2004), Transference-Focused Psychotherapy (TFP; Clarkin et al., 2006) and Schema-Focused Therapy (SFT; Kellogg \& Young, 2006). Evidence suggests that CBT is an effective treatment for BPD (Davidson et al., 2006; Leichsenring \& Leibing, 2003) with therapy focusing particularly on the development of functional new core beliefs. The therapeutic relationship is seen as a vital means for exploring the patient's style of relating to others and for fostering more adaptive future interactions. Arntz (1994) describes CBT for BPD as consisting of five stages: i) construction of working relationship, ii) symptom-management, iii) correction of thinking errors, iv) emotional processing and cognitive re-evaluation of childhood trauma and schema changes, and v) termination.

Developed by Linehan (1993), DBT has a large and robust evidence base (Bloom et al., 2012; Feigenbaum et al., 2011; Feigenbaum, 2007; Kliem et al., 2010; Linehan et al., 2006a; Panos et al., 2013). It uses strategies developed to aid enhanced regulation of emotions as well as teaching distress tolerance and using third wave approaches such as mindfulness to 
promote awareness and acceptance. Because of the large number of studies of DBT and CBT for BPD, this review focuses on potential mechanisms of change in these two treatments only.

\section{Method}

Searching, identifying and selecting studies for inclusion

Searches of paper titles, abstracts and full text content were initially performed in July and August 2012 then updated in February 2014, in Psychlnfo, CINAHL Plus, PubMed, MEDLINE and EMBASE databases. Search terms used were: a) "mechanism* change borderline personality disorder", b) "mechanism* change" and "borderline personality disorder", c) "mechanism* change" and "BPD", d) "mechanism* change" and "borderline personality disorder" and "treatment" and e) "borderline personality disorder" and "therapeutic change." Studies included in the review involved participants who:

- met standardised diagnostic criteria for BPD

- $\quad$ had received either CBT or DBT treatment for their BPD

- were treated as outpatients (due to the limited number of manualised DBT/CBT studies of inpatients or partially hospitalised patients with BPD)

- were treated within full text, peer-reviewed, empirical studies published in English since 1990 (as this was the earliest that the literature began to report CBT and DBT treatment of BPD)

- were adults (aged 18+ years) at the time of treatment (as there is a limited research presence investigating emerging BPD in adolescents)

The review excluded:

- $\quad$ single case studies 
- studies which did not ultimately produce evidence on mechanisms of change and were therefore better defined as outcome studies. To ascertain this, two questions were asked:

1) Is the studied variable theorised to be a mechanism of change in a (separately defined) outcome variable?

2) Does the data presented investigate an association/correlation between the proposed mechanistic variable and an outcome variable?

Using the five search terms within each of the aforementioned databases yielded a total of 104 references which, following a title screen, reduced to 34 abstracts for review. It was clear that 15 papers did not meet inclusion criteria and therefore 19 full texts were appraised. Nine studies were ultimately excluded for presenting outcome data only, failing to separate out potential mechanisms by treatment type, or for combining inpatient/outpatient data. One study (Stepp et al., 2008) did not strictly meet inclusion criteria as only $63 \%$ of participants met diagnostic criteria for BPD and because at least one participant was under 18 years. It was decided, however, that because of the study's relevance to the review it would still be beneficial to include, albeit with caveats. This left ten studies for inclusion.

In October 2016, identical searches to those completed in 2012 and 2014 were re-run in all five databases. This search returned 261 references, yielding a total of 18 new abstracts for review after removal of studies appraised previously and those not relevant to BPD. Eleven further full texts were reviewed and a further four studies met inclusion criteria, taking the total to 14. See figure 1 for flow chart of the review process.

\section{Studies included}

The 14 studies reviewed were published between 2000 and 2016 (Table 1). Twelve studies examined mechanisms of change in DBT and two in CBT. The two CBT studies (Gibbons et al., 2009; Wenzel et al., 2006) utilised the same sample of participants $(n=32)$ from 
a previous larger trial (Brown et al., 2004), but investigated different hypothesised mechanisms of change. Two of the DBT studies (Bedics et al., 2015; Bedics et al., 2012) also used the same sample $(n=101)$. Ten studies took place in the USA, two in Switzerland, one in Canada and one in the UK. Sample sizes ranged from 24 to 165 and combined, the studies included 961 participants of which 912 (95\%) were female. Ages ranged from 16-61 years with a mean of 31.2 years.

Analysis

Studies were evaluated based on their design and findings and measured against a critical appraisal checklist (DBC; Downs \& Black, 1998, see Appendix) which assesses the methodological quality of both randomised and non-randomised studies of healthcare interventions. Due to difficulty in ascertaining reliable scores for the final item (power analyses, item 27) which awards up to five points, this item was instead scored either ' 0 ' (no power calculation completed or power not met) or ' 1 ' (power calculation completed, and met). Therefore, a maximum score of 28 was possible (item five only is worth up to two points). A summary of each study's performance against the DBC can be found in Table 2 (DBT) or Table $3(\mathrm{CBT})$.

Across the 14 studies evaluated, three main themes emerged under which all identified mechanisms of change could be categorised, i) emotion regulation and self-control, ii) skills use and iii) therapeutic alliance and investment in treatment. Each study is described in detail below under one of these three categories.

\section{Results}

\section{Emotion regulation and self-control}

Axelrod et al. (2011) posited that greater control of emotions in BPD would lead to less impulsive behaviour which would, in turn, reduce the need to self-medicate using substances to 
regulate emotions. Females with substance dependence and BPD received a 20 week course of outpatient DBT and emotion regulation was assessed using the Difficulties in Emotion Regulation Scale (Gratz \& Roemer, 2004). Substance use was recorded for 30 days preceding treatment and for the final 30 days of treatment, corroborated by weekly self-report, clinician assessment, urine toxicology and alcohol breathalysers. The study concluded that improvements in emotion regulation explained the variance in decreased substance use frequency. Changes in substance use lost their significance when improvement in emotion regulation was controlled for.

This study has some limitations. Firstly, the authors use the term 'behavioural control' as their primary outcome but they measured this only by substance use. There are other aspects of behavioural control relevant to BPD (e.g. impulsivity, self-harm) that could have been measured to more convincingly argue the role of emotion regulation as a mechanism of change. Further, the lack of controls of course impedes the possibility of attributing emotion regulation improvements exclusively to DBT. Additionally, most DBT studies utilise lengthier treatment (12 months/40+ sessions) so it is unclear whether this study replicated a full, comparable 'dose'. The study's all-female sample does not facilitate conclusions about emotion regulation in males receiving DBT, although it is perhaps justified (and other BPD samples are also femaledominated) due to the ratio of BPD treatment-seeking females to males (currently estimated at 3:1; American Psychiatric Association, 2001), as well as the fact that current NICE (2009) guidance for BPD recommends the use of DBT treatment for females only.

Using participants from a larger randomised controlled trial (RCT), over 9 months McMain et al. (2013) used self-report measures to investigate the role of affect, problem-solving and emotional control. BPD symptoms and interpersonal function were assessed as outcomes every four months using well-known, standardised measures. The RCT compared the clinical effectiveness of DBT versus general psychiatric management (GPM) in 80 patients (67 female) diagnosed with BPD. Defining improved affect balance as an increased positive to negative ratio 
of emotions, results supported associations between improved affect balance with both reductions in symptom distress and improved interpersonal function. The researchers managed their data conscientiously; however, the final sample size in each parameter was reasonably small, limiting generalisability. Additionally, there was inadequate statistical power to test for between group differences and effects were therefore potentially confounded by the differences between DBT and GPM.

Using a primarily female sample of 41 participants with BPD, Kramer et al., (2016) compared a 20 session version of DBT-informed skills training against a treatment as usual (TAU) control condition in an RCT (DBT: $n=21$, TAU: $n=20$ ) which investigated two forms of anger: primary, adaptive, 'assertive' anger and secondary, 'rejecting' anger. The latter could be classified in BPD patients as hostility or aggression. The former is a more accepted and adaptive emotional experience in which a person's rights are rationally defended. The researchers hypothesised that the occurrence of rejecting anger would remain stable over time for both DBT and TAU but that observed expressions of primary assertive anger would increase more in DBT participants. Anger was measured both early and late in treatment using an intensive behavioural assessment of a standardised psychological interview (Perry et al., 2005). As well as finding that symptom reduction was greater in the DBT group than TAU, as expected the researchers discovered that the DBT group displayed increased use of assertive anger compared to TAU, whereas no effect was found for less productive rejecting anger. The authors link their findings to the theory that reactive angry responses may drive the state-related problematic behaviour seen in BPD (e.g. self-harm, suicidal ideation, interpersonal aggression; Brown et al., 2002). A particular strength of this study lies in its robust methodology; however, because participants were not blind to treatment condition, expectation biases may have occurred. Not uncommonly, attrition was a problem; however the researchers adequately addressed this using intent to treat analyses. Throughout the paper, the DBT administered is described as 'DBT-informed skills training' (a group format) meaning that it lacked the other 
components of standardised DBT (individual therapy sessions, therapist team consultations and between-session telephone coaching) which comprise the complete treatment. It is possible that the observed effects could be lost if the skills focus of the treatment program was diluted with comprehensive DBT. Additionally, effects were not demonstrated at follow-up which could have been due to post-treatment dropouts lowering statistical power or because the shortened treatment format may have represented an insufficient dose of DBT.

\section{Skills use}

A key aspect of DBT is the teaching of specific behavioural skills which aim to replace maladaptive behaviours with more adaptive responses (Linehan, 1993). Neacsiu et al. (2010) noted that no study to date had directly tested this mechanism of change. They investigated DBT skills use in a sample of 108 women with BPD who were participating in a 12 month RCT with a four month follow-up. Participants included 63 recurrently suicidal women and 45 women with drug dependence (there were no significant demographic differences between the two groups). Participants received either DBT or one of three control treatments: Community Treatment by Experts (CTBE), Comprehensive Validation Therapy (CVT) or TAU in conjunction with a 12-step program. Measures of DBT skills use, anger, suicidal/self-harm behaviour and depression were gathered using a combination of self-report and semi-structured interviews. Although anger suppression and expression was not found to mediate outcome, significant mediation effects did indicate that use of DBT skills fully mediated decreases in suicide attempts and depression symptom severity and an increase in the control of anger over time. Use of DBT skills also partially mediated a decrease in self-harm over time. Participants who received DBT reported using three times more skills by the end of their treatment (mean skills use increased by $15.3 \%$ ), compared to control participants (mean skills use increased by $4.6 \%$ ). At follow up, DBT participants maintained increased skill use but control participants had decreased by $5 \%$. Although this study demonstrated support for the DBT skills deficit model of BPD, it is limited by 
its primary reliance on subjective self-report as well as using retrospective methods which are subject to both memory biases and over/underreporting responder biases. Assessing skills use on a daily basis using a more objective measure would increase reliability. When using standard mediation analysis, an assumption is made that there are no confounds manipulating the mediator and outcome (Robins \& Rotnitzky, 2005) and it is possible that uncontrolled extraneous variables influenced the meditational analysis in this study such that an increase in DBT skills use was not the only variable influencing positive outcomes. Nevertheless, methodologically, this remains a robust study, reflected by the highest score awarded by the DBC.

Gibbons et al. (2009) were specifically interested in the acquisition of compensatory skills, self-understanding and perception, which they considered to be theoretically important mechanisms of change affecting outcomes in cognitive-based therapy for BPD. As part of a larger clinical trial (Brown et al., 2004), 34 participants with a primary diagnosis of BPD received 12 months of cognitive therapy tailored to BPD with self-report questionnaires used to measure self-understanding and acquisition of compensatory skills. Outcomes of depression, anxiety and quality of life were measured using well-known, validated self-report measures. The researchers found that change in compensatory skills was apparent in the BPD group and that in particular, a decrease in negative compensatory responses/negative thinking co-occurred with symptom improvement. This study used data from a larger trial which also included participants with a primary diagnosis of depression or anxiety so outcome measures were perhaps too broad to capture some of the additional symptoms experienced by those with BPD. Not uncommonly, this study relied heavily on self-report, creating the possibility of biased responding. The researchers concede that the relatively small within-study sample sizes and their associated limitations on statistical power meant that the use of a pooled database was not the best way to investigate mechanisms of change in specific treatments for specific diagnostic categories. 
Over a 12 month period, Perroud et al. (2012) investigated improved skills in mindfulness, a key component of DBT. Fifty two (predominantly female) participants with a BPD diagnosis were regularly administered the Kentucky Inventory of Mindfulness Skills (KIMS; Baer et al., 2004), a self-report questionnaire which categorises mindfulness into four discrete dimensions: observing, describing, acting with awareness and accepting without judgment. Selfreport measures of depression and hopelessness were also administered at regular intervals, as were standardised diagnostic clinician-administered assessments of BPD psychopathology. Accepting without judgement was the only dimension found to significantly increase following statistical adjustment for potential confounds. Increases in this dimension specifically correlated with improved BPD symptoms. Mindfulness is perhaps a construct inherently difficult to measure objectively so self-report may be the best way to capture it, despite potential response biases. However, this study lacked a control group, limiting the possibility of drawing conclusions about whether observed improvements are exclusive to the acquisition of the accepting without judgement skill or whether they are partially or otherwise explained by a natural change in mindfulness skills and/or correlate with an uncontrolled confound.

O'Toole et al. (2012) also studied improvements in mindfulness skills in 165 women with BPD recruited from five DBT programs. Self-report measures of perceived social support and physical and emotional well-being were used to assess outcomes. Mindfulness skills were measured using the Five Facet Mindfulness Questionnaire (FFMQ; Baer et al., 2008), a 39-item self-report measure. Mindfulness emerged as the strongest predictor of emotional well-being and women who reported greater use of mindfulness skills reported more infrequent use of healthcare services. Mindfulness was, however, unrelated to the use of prescription medication. The large sample size and robust statistical techniques add to the reliability of these findings although the voluntary and diverse recruitment process creates potential biases and as with some other studies, data relied solely on self-report. This study, nevertheless, makes an 
important contribution to the evidence regarding the role of mindfulness skills as a DBT change mechanism.

Using a multi-level repeated measures, non-randomised, uncontrolled design, Stepp et al. (2008) set out to identify possible 'active ingredients' of DBT that may account for improved BPD symptoms. Their sample of 27 participants ( $85 \%$ female) ranged in age from $16-61$ years but only $63 \%$ met diagnostic criteria for BPD. To assess BPD symptoms, the Personality Assessment Inventory-Borderline Features Scale (PAI-BOR; Morey, 1991), a 24 item self-report measure was administered at the start of each new skills module (teaching sequence: i) mindfulness, ii) interpersonal effectiveness, iii) emotion regulation and iv) distress tolerance). Skills use was assessed by weekly self-report diary cards. Analyses revealed that overall skills use produced a significant effect on PAI-BOR total scores over the course of 12 months. This finding held when analyses controlled for baseline levels of distress and diary card compliance. The methodological limitations of this study meant that it achieved the lowest score on the DBC: the researchers concede that their findings could reflect motivation rather than skills utilisation; more motivated participants would arguably also be more committed to completing diary cards. However, this confound was controlled as much as possible. Both skills use and outcome could be more reliably assessed by using blinded performance-based observer ratings. Despite the study's power-maximising design, small effect sizes could have been missed due to the small sample and the fact that one third of participants did not meet DSM-IV criteria for BPD introduces an uncontrolled confound limiting the conclusions that can be drawn about BPD from this research. The lack of a control group means that results may not be reflective of skills specific to DBT and could be a finding common to any skills utilisation program.

Within a single-blind, randomised trial of three different types of DBT, Linehan et al. (2015) aimed to ascertain the effect of DBT skills use on outcomes of suicide attempts, selfharm and mental health problems in 99 women diagnosed with BPD. Outcome measures included the Suicide Attempt Self Injury Interview (SASII; Linehan et al., 2006b) and the Suicidal 
Behaviours Questionnaire (Addis \& Linehan, 1989). Assessments were conducted by blinded independent assessors prior to treatment, every three months during the 12 month treatment and then 12 months post-treatment. The researchers' methodology dismantled DBT into the following formats: skills training plus case management (DBT-S), DBT individual therapy plus activities group (DBT-I), and standard DBT (this includes both skills training and individual therapy). Standard DBT was not shown to be superior over other forms of DBT with regards to suicide-related outcomes; all three formats were equally effective at reducing suicidality among high-risk participants. However, the two interventions which incorporated DBT skills training were more effective in reducing self-harm incidents and improving other mental health problems. This rigorously controlled, single-blind study used computerised randomisation and matching to allocate participants to their DBT program and a particular strength lies in the management of the data and control of, and statistical investigation into, potential confounds. Because participants were informed of their treatment allocation during their first therapy session, the possible effect of expectation biases can't be ruled out, however.

Barnicot et al. (2015) used a predominantly female sample of 70 participants with BPD, aiming to examine whether DBT skills use was associated with positive treatment outcomes independent of treatment processes common to most psychological therapies: therapeutic alliance, treatment credibility and self-efficacy. Skills use, the proposed change mechanism, was measured by self-report every two months and self-harm was clinician-assessed every two months using items selected from the SASII (Linehan et al., 2006b). The researchers concluded that more frequent use of DBT skills was independently associated with less frequent concurrent self-harm. This is a solid study; however, due to the use of DBT-specific terminology, it was not possible to compare skills use in a control group not receiving DBT. 


\section{Therapeutic alliance and investment in treatment}

Bedics et al. (2012) aimed to explore the therapeutic alliance as a mechanism of change on self-harm outcomes in DBT. One hundred and one females were randomised to receive either DBT or a control condition, Community Treatment by Experts (CTBE). As well as meeting criteria for BPD, all participants had a history of self-harm and at least one incident in the eight weeks prior to commencing the study. The quality of the therapeutic alliance was rated by patients using the Structural Analysis of Social Behaviour (SASB; Benjamin, 1974). Results showed that in comparison to CTBE participants, DBT participants reported their therapists as increasingly more affirming, protecting, and controlling during treatment. Additionally, DBT participants reported a stronger association between increased therapist affirmation and protection with decreased self-harm. Despite the strength of the RCT data, the reasonable sample size and the use of multiple time points to assess symptomatic change and the therapeutic relationship, this study has some limitations. Assessment of BPD symptoms was limited to self-harm only and the researchers note the value that further research could add in extending these results to other relevant domains. Additionally, reliability of the data is limited because of the lack of clinician-recorded or blinded observations.

Continuing their research, Bedics et al. (2015) used DBT and CTBE comparison data from their previous sample (Bedics et al., 2012), this time employing the California Psychotherapy Alliance Scale (CALPAS; Gaston, 1991) to investigate the association between different components of the alliance and BPD outcomes (suicide attempts, self-harm, introject and depression) which were measured using standardised, validated tools. No differences were found between patient ratings of the alliance between the two treatments, however a reduction in self-harm was associated with an increase in patient-rated total alliance in DBT but not in CTBE. Although it did not quite reach significance, researchers also discovered that DBT participants who perceived greater understanding and involvement from their therapist reported reductions in self-harm. As per their rationale, investigating specific facets of the alliance 
highlighted mechanisms that may not be revealed when focusing on total alliance ratings, however, the researchers did not control for the possibility that early symptom improvement may have influenced alliance ratings, causing subsequent changes in symptoms.

Turner (2000) tested the effects of DBT versus a Client-Centred Treatment control condition (CCT) in a naturalistic evaluation of 24 (primarily female) participants with a diagnosis of BPD. In order to understand its role in differences in outcomes (depression, anxiety, anger, self-harm/suicidality, hospitalisation) between the two therapies, the quality of the therapeutic alliance was measured using the Helping Relationship Questionnaire (HRQ; Luborsky, 1984). Participants were randomly assigned to receive either DBT or CCT and outcomes were evaluated using a combination of self-report and a blind rating assessor. Differences in ratings of the quality of the therapeutic alliance were found to account for significant variance in outcomes across both DBT and CCT but no significant difference in therapeutic alliance was observed between the two treatments. This suggests that the alliance accounted for as much variance in symptom improvement as did differences in the treatment conditions themselves. Researchers rated the quality of the alliance at one single time point rather than measuring a change (improvement) in alliance over time, making it harder to infer its role as a mechanism of change linked explicitly to improved BPD symptoms. Like others, this study relied heavily on self-report within a relatively small sample but the use of randomisation and controls contribute to the reliability of these important findings.

Wenzel et al. (2006) proposed that change in dysfunctional beliefs, reduction in hopelessness, and improvement in attitude toward treatment all function as mechanisms of change in CBT for BPD. Using data from 32 participants diagnosed with BPD as part of a wider clinical trial (Brown, et al., 2004), the researchers conducted clinical evaluations at baseline, six months and 12 months then again at six months follow-up. Baseline assessments involved clinician-administered interviews, self-report questionnaires and review of treatment histories. Attitude towards treatment was measured using the Attitudes and Expectations Questionnaire 
(ERQ; adapted from Elkin et al. (1989)). Results showed that $66.7 \%$ of participants who had positive attitudes toward treatment no longer met criteria for BPD after 12 months of treatment, compared to $14.3 \%$ of participants with a negative attitude toward treatment. This may be a spurious link, however; it is not clarified how changes in attitude towards treatment specifically influence outcome and without the benefit of data obtained at more than one time point it is perhaps not reliably described as a mechanism of change. The researchers investigated other hypothesised mechanisms of change concluding, in support of their hypotheses, that reductions in hopelessness were associated with significant reductions in borderline beliefs. However, this conclusion does not shed much light on the specific processes by which change occur, as both belief change and reduction in hopelessness might be more reliably classed as outcomes rather than change mechanisms. Further, the small sample size precludes the possibility of making generalisable inferences to larger samples and the standard critique of self-report measures also applies, although the use of clinician-administered assessments and treatment records did introduce more objective ratings.

\section{Discussion}

Results from this review show that there are at least three distinct categories of mechanisms of change in DBT and CBT for BPD. Empirical support for improvements in emotion regulation and behavioural control as change mechanisms in DBT is perhaps unsurprising given that Linehan's (1993) DBT biosocial theory views BPD as a disorder of persistent emotional dysfunction occurring largely due to deficits in the ability to regulate difficult emotions and because of emotional instability and vulnerability. By contrast, no studies reviewed investigated emotion regulation and self-control in CBT, which, again, is perhaps unsurprising given that the core aim of CBT for BPD focuses more on dysfunctional schema identification and cognitive restructuring (Arntz, 1994). Axelrod et al (2011) discovered an association between emotion regulation and behavioural control in DBT, although both variables 
might be considered both mechanisms of change and outcomes in their own right. Similarly, as well as discovering a link between improved affect balance and reductions in symptom distress, McMain et al., (2013) found an association between balanced affect and improved interpersonal function, a key component in DBT skills training. Also supporting a link between emotion regulation and skills use, Kramer et al. (2016) showed that receipt of a DBT skills training module was associated with improved ability to use productive, assertive anger, an association also apparent in Neacsiu et al.'s (2010) mediation analysis which concluded that the frequency of DBT skills use by patients with BPD was associated with an increase in control of anger over time.

In addition to Neacsiu et al. (2010), several DBT studies (Barnicot et al., 2015; Linehan et al., 2015; O'Toole et al., 2012; Perroud et al., 2012; Stepp et al., 2008) provided some support for Linehan's (1993) skills deficit theory of BPD suggesting that acquisition of new skills is associated with better DBT outcomes. Indeed, a study of 49 women found that both mindfulness and crisis survival skills were practiced frequently by DBT participants and that the majority practiced their DBT-learned skills on most treatment days (Lindenboim et al., 2007). Arntz (1994) lists 'correction of thinking errors' as one of five main components to be addressed in CBT for BPD. It is therefore again encouraging, yet unsurprising, that Gibbons et al. (2009) concluded that compensatory skills use was association with reductions in negative cognitions which correlated with BPD symptom improvement.

Across a range of psychotherapies, the therapeutic alliance is considered helpful in retaining patients in therapy as well as contributing to positive outcomes (Horvarth \& Luborsky, 1993). Patients view a trusting alliance as something to be prioritised (Morris et al., 2014). However, it remains a difficult concept to quantify and could easily be conflated with other mechanisms of change such that its role as an independent factor becomes less clear. The most sensible definition for considering therapeutic alliance as a mechanism of change might be 
to measure change in the alliance over time to show that as it develops (and hopefully improves) so BPD symptoms reduce - a positive, measureable outcome.

Because of their similarity, therapeutic alliance and investment in treatment were clustered to form one category in the current review but examination of both proved problematic in terms of identifying isolated processes which could reliably be classed as mechanisms of change. Barnicot et al.'s (2015) study into the association between DBT skills use and treatment outcome (self-harm, drop-out) investigated the mediating effect of three common treatment processes but of the three, both therapeutic alliance and treatment credibility were not found to be linked with decreased self-harm. More promisingly, Wenzel et al. (2006) found that a positive attitude towards treatment was associated with a reduction in BPD symptoms in CBT although it was unclear how much this factor alone was responsible for patients no longer meeting diagnostic criteria for BPD post-treatment. Exploring components of the therapeutic alliance in further detail, Bedics et al., (2015) discovered that participants' who perceived greater understanding and involvement from their therapist reported a reduction in self-harm. This fits with Linehan's (1993) model as instead of the invalidating environment that BPD patients are accustomed to, therapists provide warm, emotionally-validating settings, fostering increased emotional regulation and decreased instability and impulsivity (which manifest in behaviours such as deliberate self-harm).

Therapeutic alliance and investment in treatment are examples of non-specific processes theorised to be common across all psychological therapies, as opposed to specific effects that are produced by different therapists/models (see Wampold (2001) for review of the value of specific versus non-specific processes in psychotherapy mechanism research and Lynch et al. (2006) for a discussion of theorised common and unique mechanisms in DBT treatment). Interestingly, although Bedics et al. (2012) and Turner (2000) both concluded that a more positively-perceived alliance was associated with improved DBT outcomes, they produced contradicting evidence on the importance of the alliance as a positive change process. Bedics et 
al. (2012) found that the alliance was reported more favourably in DBT than controls whereas Turner (2000) found no significant difference in patient-reported alliance between DBT and controls. Nevertheless, the importance of the therapeutic alliance in the studies reviewed is a finding in agreement with a review of factors predicting outcome in BPD treatment (Barnicot et al., 2012) and is particularly promising given the difficulty BPD patients have with interpersonal relationships. Martin et al.'s (2000) meta-analysis of studies measuring alliance concluded that the overall relationship between the alliance and outcome is moderate but consistent regardless of any hypothesised confounds. They found great diversity in measures of alliance, suggesting that this research may not be easily replicable, adding to the difficult task of producing robust evidence of the alliance as a mechanism of change.

As well as the inherent risk of this search omitting relevant studies, this review was limited by ultimately being primarily DBT-focused with little CBT evidence. This is likely due to the prominence of DBT in the most current BPD clinical guideline (NICE, 2009) as well as the fact that DBT was created specifically for BPD. It explains why the DBT model more aptly describes the mechanisms of change identified herewith than the CBT model. This does, however, suggest that further research into mechanisms of change in cognitive therapy for BPD is warranted, especially as NICE (2009) advises that should this data be produced, future revisions may recommend $\mathrm{CBT}$ for $\mathrm{BPD}$. The empirical data reviewed highlights the difficulty in demonstrating causality, much of the evidence relying on associative relationships, and the majority of studies revealed difficulties in obtaining large enough sample sizes and in establishing satisfactory scientific rigour from which to base conclusions. Whether some variables were classed as mechanisms of change or could more reliably be considered as outcomes was also somewhat muddied. Indeed, in their study of DBT partial hospitalisation, Yen et al. (2009) concluded that, "BPD is a complex, heterogeneous disorder for which there is no single pathognomonic criterion, so that each criterion should be considered individually in determining its potential effect on treatment outcomes." 
Further robust research and hypothesis testing will help to corroborate the identified mechanisms and attempts to establish causality would be highly beneficial in concluding which components of therapy to focus on. This data could assist practitioners in testing the efficacy of briefer interventions that incorporate the specific mechanisms that are most likely to lead to positive outcomes, particularly benefitting those for whom only brief treatments are available.

Encouragingly, there was a large increase in the number of relevant studies published between the 2012 and 2016 searches, with more than a quarter of the studies that met inclusion criteria being published in the last two years. Demonstrating that this is a research-worthy area of growing interest, searches also revealed several studies of mechanisms of change in other treatments for BPD such as TFP and SFT.

\section{Conclusion}

There are several potential mechanisms of change associated with the theoretical underpinnings of BPD treatment (Lynch et al., 2006) and this review is a start in a long journey towards being able to confirm which specific mechanisms are active in treatments for such a complex, challenging disorder. Three broad categories of mechanism of change were identified which are well-explained by Linehan's (1993) DBT biosocial model of BPD: initial deficits in emotion regulation and self-control are improved via the therapeutic alliance and investment in treatment which result in increased skills use leading to favourable outcomes on mood and anxiety symptoms, and on measures of BPD symptoms including self-harm, impulsivity, substance misuse and borderline beliefs.

\section{Appendix}

This has been attached as a separate document. 


\section{References}

Addis, M \& Linehan, M.M. (1989). Predicting suicidal behaviour: psychometric properties of the Suicidal Behaviours Questionnaire. Poster presented at: Annual Meeting of the Association for the Advancement Behaviour Therapy; November 2-5, 1989; Washington, DC.

American Psychiatric Association (2013). Diagnostic and Statistical Manual of Mental Disorders (5 $5^{\text {th }}$ Edition). Arlington, VA: American Psychiatric Publishing.

American Psychiatric Association (2001). Practice guideline for the treatment of patients with borderline personality disorder-introduction. American Journal of Psychiatry, 158, 1-52.

Axelrod, S. R., Perepletchikova, F., Holtzman, K. \& Sinha, R. (2011). Emotion regulation and substance use frequency in women with substance dependence and borderline personality disorder receiving dialectical behaviour therapy. The American Journal of Drug and Alcohol Abuse, 37, 37-42.

Arntz, A. (1994). Treatment of borderline personality disorder: A challenge for cognitive behavioural therapy. Behaviour, Research and Therapy, 32, 419-430.

Baer, R. A., Smith, G. T. \& Allen, K. B. (2004). Assessment of mindfulness by self-report: The Kentucky Inventory of Mindfulness Skills. Assessment, 11, 191-206.

Baer, R. A., Smith, G. T., Lykins, E., Button, D., Krietemeyer, J., Sauer, S., et al. 
(2008). Construct validity of the Five Facet Mindfulness Questionnaire in meditating and non-meditating samples. Assessment, 15, 329-342.

Barnicot, K., Gonzalez, R., McCabe, R., \& Priebe, S., (2015). Skills use and common treatment processes in dialectical behaviour therapy for borderline personality disorder, Journal of behavior therapy and experimental psychiatry, 52, 147-156.

Barnicot, K., Katsakou, C., Bhatti, N., Savill, M., Fierns, N. \& Priebe, S. (2012).

Factors predicting the outcome of psychotherapy for borderline personality disorder: a systematic review. Clinical Psychology Review, 32, 400-412.

Bateman, A.W. \& Fonagy, P. (2008). 8-year follow-up of patients treated for borderline personality disorder: Mentalization-based treatment versus treatment as usual. American Journal of Psychiatry 165, 631-638.

Bateman, A. W. \& Fonagy, P. (2004). Psychotherapy for borderline personality disorder: Mentalization-based treatment. Oxford: Oxford University Press.

Beck, A. T., Freeman, A., \& Davis, D. D. (2004). Cognitive therapy of personality disorders. (2 $2^{\text {nd }}$ Edition). New York: Guilford.

Bedics, J., D., Atkins, D. C., Harned, M. S. \& Linehan, M. M. (2015). The therapeutic alliance as a predictor of outcome in dialectical behaviour therapy versus nonbehavioural psychotherapy by experts for borderline personality disorder. Psychotherapy (Chic), 52, 67-77. 
Bedics, J. D., Atkins, D. C., Comtois, K. A. \& Linehan, M. M. (2012). Treatment differences in the therapeutic relationship and introject during a 2-year randomised controlled trial of dialectical behaviour therapy versus non-behavioural psychotherapy by experts for borderline personality disorder. Journal of Consulting and Clinical Psychology, 80, 66-77.

Bender, D. S., Dolan, R. T., Skodol, A. E., Sanislow, C. A., Dyck, I. R., McGlashan, T. H., Shea, M. T., Zanarini, M. C., Oldham, J. M. \& Gunderson, J. G. (2001). American Journal of Psychiatry, 158, 295-302.

Benjamin, L. S. (1974). Structural analysis of social behaviour. Psychological Review, 81, 392-425.

Bloom, J. M., Woodward, E. N., Sasmaras, T., Pantalone, D. W. (2012). Use of dialectical behaviour therapy in inpatient treatment of borderline personality disorder: a systematic review. Psychiatric Services, 63, 881-888.

Brown, G. K., Newman, C. F., Charlesworth, S. E., Crits-Christoph, P., \& Beck, A. T. (2004). An open clinical trial of cognitive therapy for borderline personality disorder. Journal of Personality Disorders, 18, 257-271.

Brown, M., Comtois, K. A., \& Linehan, M. M. (2002). Reasons for suicide attempts and non-suicidal self-injury in women with borderline personality disorder. Journal of Abnormal Psychology, 111, 198-202. 
Clarkin, J. F. \& Levy, K. N. (2006). Psychotherapy for patients with borderline personality disorder: Focusing on the mechanisms of change. Journal of Clinical Psychology, 62, 405-410.

Clarkin, J. F., Yeomans, F. E. \& Kernberg, O. (2006). Psychotherapy for Borderline Personality, Focusing on Object Relations. American Psychiatric Publishing.

Coid J., Yang M, Tyrer, P., Roberts, A., \& Ullrich, S. (2006). Prevalence and correlates of personality disorder in Great Britain. British Journal of Psychiatry, 188, 423431.

Comtois, K. A., Russo, J., Snowden, M., Srebnik, D., Ries, R. \& Roy-Byrne, P. (2003). Factors associated with high use of public mental health services by persons with borderline personality disorder. Psychiatric Services, 54, 1149-1154.

Davidson, K., Norrie, J., Tyrer, P., Gumley, A. I., Tata, P., Murray, H., \& Palmer, S. (2006). The effectiveness of cognitive behaviour therapy for borderline personality disorder: Results from the BOSCOT Trial. Journal of Personality Disorders, 20, 450465.

de Ruiter, C. \& Greeven, P. J. G. (2000). Personality disorders in a Dutch forensic psychiatric sample: convergence of interview and self-report measures. Journal of Personality Disorders, 14, 162-170.

Downs, S. H. \& Black, N. (1998). The feasibility of creating a checklist for the 
assessment of the methodological quality both of randomised and non-randomised studies of health care interventions. Journal of Epidemiological Community Health, 52 , 377-384.

Elkin, I., Shea, M.T., Watkins, J.T., Imber, S.D., Sotsky, S.M., Collins, J.F., Glass, D. R., Pilkonis, P. A., Leber, W. R., Docherty, J. P., Fiester, S. J. \& Parloff, M. B. (1989). National Institute of Mental Health Treatment of Depression Collaborative Research Program: General effectiveness of treatments. Archives of General Psychiatry, 46, 971982.

Elliott, R. (2010). Psychotherapy change process research: realizing the promise. Psychotherapy Research, 20, 123-235.

Feigenbaum, J. D., Fonagy, P., Pilling, S. Jones, A., Wildgoose, A. \& Bebbington, P. E. (2011). A real-world study of the effectiveness of DBT in the UK National Health Service. British Journal of Clinical Psychology, 51, 121-141.

Feigenbaum, J. (2007). Dialectical behaviour therapy: An increasing evidence base. Journal of Mental Health, 16, 51-68.

Gaston, L. (1991). Reliability and criterion-related validity of the California Psychotherapy Alliance Scales - Patient Version. Journal of Consulting and Clinical Psychology, 3, 68-74.

Gibbons, M. B. C., Crits-Christoph, P., Barber, J. P., Wiltsey Stirman, S., Gallop, R. 
Goldstein, L. A., Temes, C. M. \& Ring-Kurtz, S. (2009). Unique and common mechanisms of change across cognitive and dynamic psychotherapies. Journal of Consulting and Clinical Psychology, 77, 801-813.

Gratz, K. L. \& Roemer, L. (2004). Multidimensional assessment of emotion regulation and dysregulation: Development, factor structure, and initial validation of the difficulties in emotion regulation scale. Journal of Psychopathological Behaviour Assessment, 26, 41-54.

Horvath, A. O. \& Luborsky, L. (1993). The role of the therapeutic alliance in psychotherapy. Journal of Consulting and Clinical Psychology. 61, 561-573.

Kazdin, A. E. (2007). Mediators and mechanisms of change in psychotherapy research. Annual Review of Clinical Psychology, 3, 1-27.

Kellogg, S. H. and Young, J. E. (2006). Schema therapy for borderline personality disorder. Journal of Clinical Psychology, 62, 445-458.

Kramer, U., Pascual-Leone, A., Berthoud, L., De Roten, Y., Marquet, P., Kolly, S., Despland, J., \& Page, D. (2016). Assertive anger mediates effects of dialectical behaviour-informed skills training for borderline personality disorder: A randomized controlled trial. Clinical Psychology and Psychotherapy, 23, 189-202.

Kliem, S. Kröger, C. \& Kosfelder, J. (2010). Dialectical behaviour therapy for borderline personality disorder: a meta-analysis using mixed-effects modelling. Journal of Consulting and Clinical Psychology, 78, 936-951. 
Leichsenring, F. \& Leibing, E. (2003). The effectiveness of psychodynamic therapy and cognitive behaviour therapy in the treatment of personality disorders: a metaanalysis, American Journal of Psychiatry, 160, 1223-1232.

Lindenboim, N., Comtois, K. A. \& Linehan, M. M. (2007). Skills practice in dialectical behaviour therapy for suicidal women meeting criteria for borderline personality disorder. Cognitive and Behavioural Practice, 14, 147-156.

Linehan, M. M. Korslund, K. E., Harned, M. S., Gallop, R. J., Lungu, A., Neasciu, A. D., McDavid, J., Comtois, K. A., \& Murray-Gregory, A. M. (2015). Dialectical behaviour therapy for high suicide risk in individuals with borderline personality disorder: A randomised clinical trial and component analysis. JAMA Psychiatry, 72, 475-482.

Linehan, M., M. Comtois, K. A., Murray, A. M., Brown, M. Z., Gallop, R. J., Heard, H. L., Korslund, K. E., Tutek, D. A., Reynolds, S. K., Lindenboim, N. (2006a). Two-year randomized controlled trial and follow-up of dialectical behaviour therapy verses therapy by experts for suicidal behaviours and borderline personality disorder. Archives of General Psychiatry, 63, 757-766.

Linehan, M. M., Comtois, K. A., Brown, M. Z., Heard, H. L. \& Wager, A. (2006b).

Suicide Attempt Self-Injury Interview (SASII): Development, reliability, and validity of a scale to assess suicide attempts and intentional self-injury. Psychological Assessment, $18,303-312$.

Linehan, M. M. (2000). The empirical basis of dialectical behaviour therapy: 
Development of new treatments versus evaluation of existing treatments. Clinical Psychology: Science and Practice, 7, 113-119.

Linehan, M. M. (1993). Cognitive-behavioural treatment of borderline personality disorder. New York: The Guilford Press.

Luborsky, L. (1984). Principles of psychoanalytic psychotherapy. New York: Basic Books.

Lynch, T. R., Chapman, A. L., Rosenthal, M. Z., Kuo, J. R. \& Linehan, M. M. (2006). Mechanisms of change in dialectical behaviour therapy: theoretical and empirical observations. Journal of Clinical Psychology, 62, 459-480.

Martin, D. J., Garske, J. P. \& Davis, M. K. (2000). Relation of the therapeutic alliance with outcome and other variables: A meta-analytic review. Journal of Consulting and Clinical Psychology, 68, 438-450.

McMain, S., Links, P., Guimond, T., Wnuk, S., Eynan, R., Bergmans, Y., Warwar, S. (2013). An exploratory study of the relationship between changes in emotion and cognitive processes and treatment outcome in borderline personality disorder. Psychotherapy Research, 23, 658-673.

Morey, L. (1991). Personality assessment inventory: Professional manual. Odessa, FL: Psychological Assessment Resources.

Morris, C., Smith, I. \& Alwin, N. (2014). Is contact with adult mental health services 
helpful for individuals with diagnosable BPD? A study of service users' views in the UK. Journal of Mental Health, 23, 251-255.

National Institute for Health and Clinical Excellence (2009). Borderline Personality Disorder: Treatment and management. CG78. London: National Institute for Health and Clinical Excellence.

Neacsiu, A. D., Rizvi, S. L. \& Linehan, M. M. (2010). Dialectical behaviour therapy skills use as a mediator and outcome of treatment for borderline personality disorder. Behaviour, Research and Therapy, 48, 832-839.

O'Toole, S. K., Diddy, E., \& Kent, M. (2012). Mindfulness and emotional well-being in women with borderline personality disorder. Mindfulness, 3, 117-123.

Panos, P. T., Jackson, J. W., Hasan, O. \& Panos, A. (2014). Meta-analysis and systematic review assessing the efficacy of dialectical behaviour therapy (DBT). Research on Social Work Practice, 24, 213-223.

Perroud, N. Nicastro, R., Jermann, F. \& Huguelet, P. (2012). Mindfulness skills in borderline personality disorder patients during dialectical behaviour therapy: Preliminary results. International Journal of Psychiatry in Clinical Practice, 16, 189-196.

Perry, J. C., Fowler, J. C., \& Semeniuk, T. T. (2005). An investigation of tasks and techniques associated with dynamic interview adequacy. Journal of Nervous and Mental Disease, 193, 136-139. 
Robins, J., \& Rotnitzky, A. (2005). Estimation of treatment effects in randomised trials with non-compliance and dichotomous outcome using structural mean models. Biometrika, 91, 763-783.

Stepp, S., Epler, A., Jahng, S \& Trull, T. (2008). The effect of dialectical behaviour therapy skills use on borderline personality disorder features. Journal of Personality Disorders, 22, 549-563.

Sulzer, S., H., Muenchow, E., Potvin, A., Harris, J. \& Gigot, G. (2015). Improving patient-centred communication of the borderline personality disorder diagnosis. Journal of Mental Health, 25, 5-9.

Turner, R. M. (2000). Naturalistic evaluation of dialectical behaviour therapy-oriented treatment for borderline personality disorder. Cognitive and Behavioural Practice, 7, 413419.

Wampold, B. E. (2001). The great psychotherapy debate: Model, methods, and findings. Mahwah, NJ: Lawrence Erlbaum Associates.

Wenzel, A., Chapman, J. E., Newman, C. F., Beck, A. T. \& Brown, G. K. (2006). Hypothesised mechanisms of change in cognitive therapy for borderline personality disorder. Journal of Clinical Psychology, 62, 503-516.

Yen, S., Johnson, J., Costello, E. \& Simpson, E. B. (2009). A 5-day dialectical 
behaviour therapy partial hospital program for women with borderline personality disorder: Predictors of outcome from a 3-month follow-up study. Journal of Psychiatric Practice, 15, 173-182. 


\section{Figures}

\section{Figure 1: $\quad$ Flow chart of review database}

\section{0-2014}

Electronic database

search results

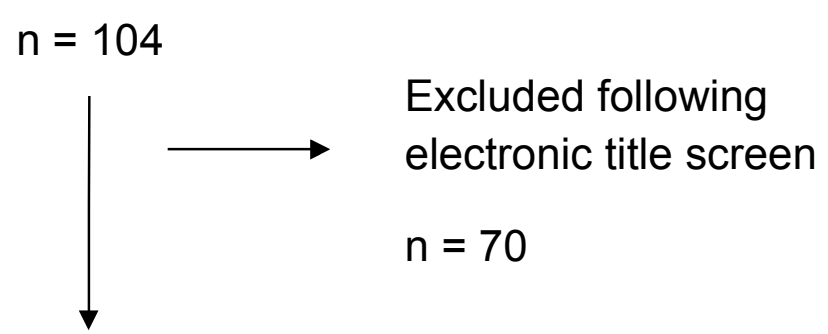

Abstracts screened

$$
\mathrm{n}=34
$$
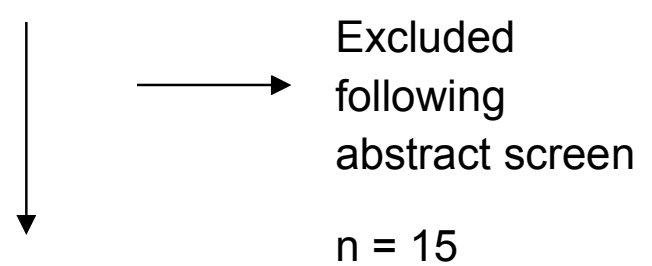

Full texts screened

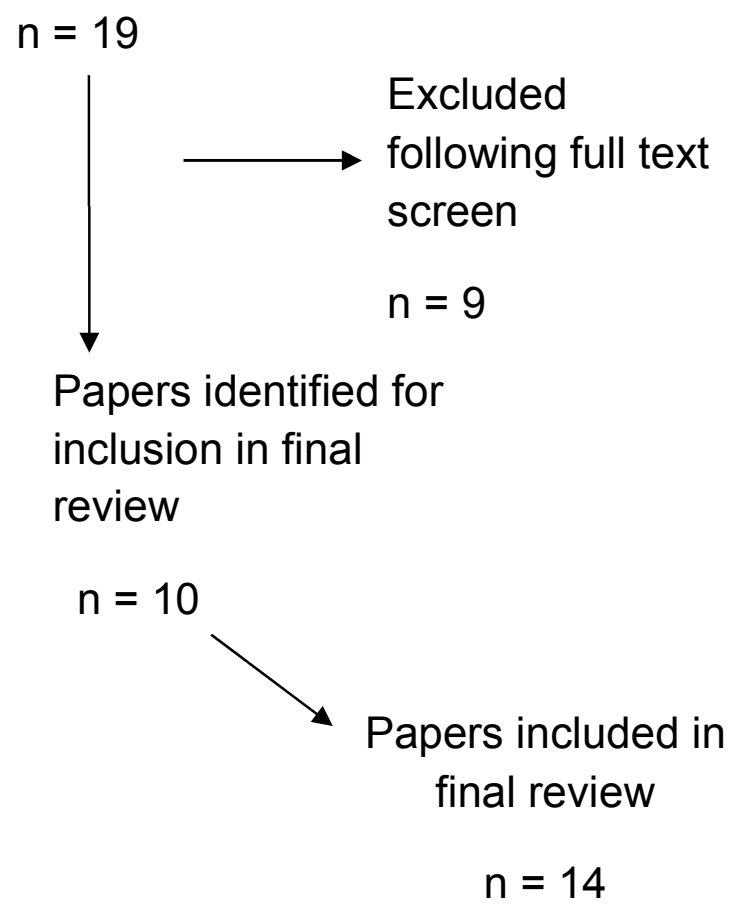

Papers identified for inclusion in final

$$
n=10
$$

final review

\section{$\underline{2014-2016}$}

Electronic database search results

$\mathrm{n}=261$

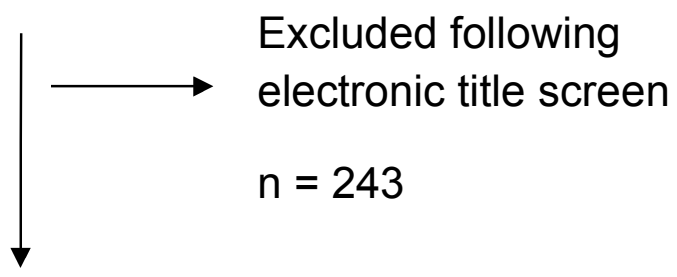

Abstracts screened

$$
\mathrm{n}=18
$$

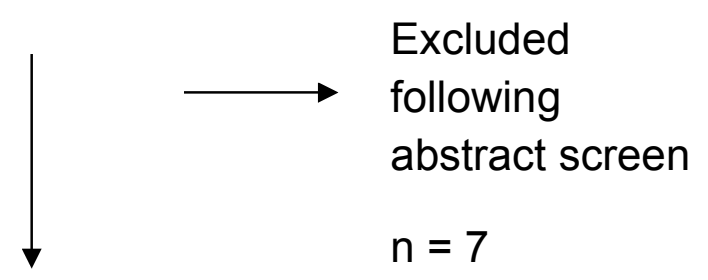

Full texts screened

$$
\mathrm{n}=11
$$

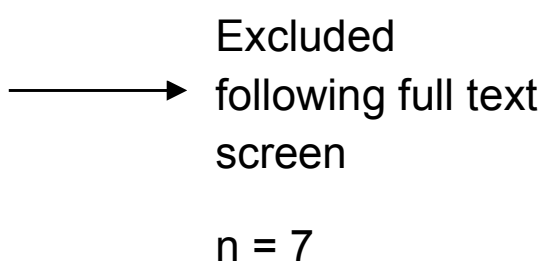

Papers identified for inclusion in final review

$$
\mathrm{n}=4
$$




\section{Tables}

\begin{tabular}{|c|c|c|c|c|c|c|c|c|}
\hline Author(s) & $\begin{array}{l}\text { Publication } \\
\text { year }\end{array}$ & Country & $\begin{array}{l}\text { Primary } \\
\text { therapeutic } \\
\text { orientation }\end{array}$ & $\begin{array}{l}\text { Control } \\
\text { group? }\end{array}$ & $\begin{array}{l}\text { Sample } \\
\text { size }\end{array}$ & Participants & $\begin{array}{l}\text { Mechanism(s) of } \\
\text { change }\end{array}$ & Main findings \\
\hline $\begin{array}{l}\text { Axelrod et } \\
\text { al. }\end{array}$ & 2011 & USA & DBT & No & $\mathrm{n}=27$ & $\begin{array}{l}27 \text { women with BPD and substance } \\
\text { dependence. Mean age }=38.0 \mathrm{yrs} \\
\text { (range }=27-51 \mathrm{yrs} \text { ) }\end{array}$ & $\begin{array}{l}\text { Improvements in } \\
\text { emotion regulation }\end{array}$ & $\begin{array}{l}\text { Improved emotion regulation } \\
\text { can account for increased } \\
\text { behavioural control }\end{array}$ \\
\hline $\begin{array}{l}\text { Barnicot } \\
\text { et al. }\end{array}$ & 2015 & UK & DBT & No & $\mathrm{n}=70$ & $\begin{array}{l}63 \text { women and } 7 \text { men with BPD. } \\
\text { Mean age }=32.0 \text { yrs (s.d. }=10.2 \text { yrs })\end{array}$ & $\begin{array}{l}\text { Improvements in DBT } \\
\text { skills use }\end{array}$ & $\begin{array}{l}\text { More frequent use of DBT } \\
\text { skills was independently } \\
\text { associated with less frequent } \\
\text { self-harm }\end{array}$ \\
\hline $\begin{array}{l}\text { Bedics et } \\
\text { al }\end{array}$ & 2015 & USA & DBT & Yes & $n=101$ & $\begin{array}{l}101 \text { women with BPD. Mean } \\
\text { age }=29.3 \text { yrs (s.d. }=7.5 y r s)\end{array}$ & $\begin{array}{l}\text { Facets of therapeutic } \\
\text { alliance }\end{array}$ & $\begin{array}{l}\text { Reduction in self-harm } \\
\text { associated with increase in } \\
\text { patient-rated total alliance in } \\
\text { DBT group }\end{array}$ \\
\hline $\begin{array}{l}\text { Bedics et } \\
\text { al }\end{array}$ & 2012 & USA & DBT & Yes & $n=101$ & $\begin{array}{l}101 \text { women with BPD. Mean } \\
\text { age }=29.3 \mathrm{yrs} \text { (s.d.=7.5yrs) }\end{array}$ & $\begin{array}{l}\text { Personality factors and } \\
\text { intrapsychic change, } \\
\text { perception of } \\
\text { therapeutic alliance }\end{array}$ & $\begin{array}{l}\text { DBT patients reported self- } \\
\text { affirmation, protection, love } \\
\text { and less self-attack than } \\
\text { controls }\end{array}$ \\
\hline $\begin{array}{l}\text { Gibbons } \\
\text { et al. }\end{array}$ & 2009 & USA & CBT & Yes & $n=32$ & $\begin{array}{l}28 \text { women and } 4 \text { men with BPD. } \\
\text { Mean age }=29.0 \text { yrs (range }=20-55 \\
\text { yrs) [from Brown et al., 2004] }\end{array}$ & $\begin{array}{l}\text { Self-understanding } \\
\text { and compensatory } \\
\text { skills }\end{array}$ & $\begin{array}{l}\text { Change in compensatory } \\
\text { skills observed in CBT group }\end{array}$ \\
\hline $\begin{array}{l}\text { Kramer et } \\
\text { al. }\end{array}$ & 2016 & Switzerland & DBT & Yes & $\mathrm{n}=41$ & $\begin{array}{l}36 \text { women and } 5 \text { men with BPD. } \\
\text { Mean age }=34.4 \text { yrs (s.d. }=9.1 \mathrm{yrs})\end{array}$ & $\begin{array}{l}\text { Productive use of ager } \\
\text { as an emotion and } \\
\text { DBT skills use }\end{array}$ & $\begin{array}{l}\text { The use of DBT skills resulted } \\
\text { in greater symptom reduction } \\
\text { in the DBT skills group. }\end{array}$ \\
\hline $\begin{array}{l}\text { Linehan et } \\
\text { al. }\end{array}$ & 2015 & USA & DBT & Yes & $n=99$ & $\begin{array}{l}99 \text { women aged } 18-60 \text { yrs (no mean } \\
\text { age reported). }\end{array}$ & DBT skills use & $\begin{array}{l}\text { Standard DBT was not } \\
\text { superior to other forms of } \\
\text { DBT on suicide outcomes but } \\
\text { was superior in reducing self- } \\
\text { harm and improving other } \\
\text { mental health problems. }\end{array}$ \\
\hline $\begin{array}{l}\text { McMain et } \\
\text { al. }\end{array}$ & 2013 & Canada & DBT & Yes & $\mathrm{n}=80$ & $\begin{array}{l}67 \text { women and } 13 \text { men with BPD. } \\
\text { Mean age }=32.6 \mathrm{yrs}(\mathrm{s} . \mathrm{d}=10.1 \mathrm{yrs})\end{array}$ & $\begin{array}{l}\text { Affect balance, } \\
\text { problem solving and } \\
\text { ability to identify and } \\
\text { describe emotions }\end{array}$ & $\begin{array}{l}\text { Participants with } \\
\text { improvements in affect } \\
\text { balance, problem solving, } \\
\text { and the ability to identify } \\
\text { and describe emotions } \\
\text { showed greater } \\
\text { improvements in symptom } \\
\text { distress and interpersonal } \\
\text { function, }\end{array}$ \\
\hline
\end{tabular}




\begin{tabular}{|c|c|c|c|c|c|c|c|c|}
\hline $\begin{array}{l}\text { Neacsiu et } \\
\text { al. }\end{array}$ & 2010 & USA & DBT & Yes & $\mathrm{n}=108$ & $\begin{array}{l}63 \text { recurrently suicidal women with } \\
\text { BPD and } 45 \text { women with BPD. Mean } \\
\text { age }=31.4 \text { yrs (s.d. }=7.4 \text { yrs) }\end{array}$ & $\begin{array}{l}\text { Increasing use of DBT } \\
\text { skills }\end{array}$ & $\begin{array}{l}\text { DBT skills use mediated } \\
\text { decreases in suicide attempts } \\
\text { and depression }\end{array}$ \\
\hline $\begin{array}{l}\text { O'Toole et } \\
\text { al. }\end{array}$ & 2012 & USA & DBT & No & $n=165$ & $\begin{array}{l}165 \text { women with BPD. Mean } \\
\text { age }=37.1 \mathrm{yrs}(\mathrm{s} . \mathrm{d} .=12.04 \mathrm{yrs})\end{array}$ & Mindfulness skills & $\begin{array}{l}\text { The use of mindfulness skills } \\
\text { predicted emotional well- } \\
\text { being. Women reporting } \\
\text { greater use of mindfulness } \\
\text { skills also reported less use } \\
\text { of healthcare services } \\
\text { although there was no } \\
\text { associated change to } \\
\text { prescription levels. }\end{array}$ \\
\hline $\begin{array}{l}\text { Perroud et } \\
\text { al. }\end{array}$ & 2012 & Switzerland & DBT & No & $n=54$ & $\begin{array}{l}47 \text { women and } 7 \text { men with BPD and } \\
\text { suicidal/self-harm behaviour. Mean } \\
\text { age }=30.5 \mathrm{yrs} \text { (s.d.=7.7 yrs) }\end{array}$ & $\begin{array}{l}\text { Mindfulness and } \\
\text { acceptance }\end{array}$ & $\begin{array}{l}\text { Increase in skill of accepting } \\
\text { without judgement correlated } \\
\text { with improvements in BPD } \\
\text { symptoms }\end{array}$ \\
\hline $\begin{array}{l}\text { Stepp et } \\
\text { al. }\end{array}$ & 2008 & USA & DBT & No & $n=27$ & $\begin{array}{l}23 \text { women and } 4 \text { men. } 63 \% \text { met } \\
\text { DSM-IV criteria for BPD. Mean } \\
\text { age }=30.4 \text { (range }=16-61 \mathrm{yrs} \text { ) }\end{array}$ & $\begin{array}{l}\text { Increased DBT skills } \\
\text { use }\end{array}$ & $\begin{array}{l}\text { Increased overall DBT skills } \\
\text { use had a significant effect on } \\
\text { measure of BPD symptoms. }\end{array}$ \\
\hline Turner & 2000 & USA & DBT & Yes & $n=24$ & $\begin{array}{l}19 \text { women and } 5 \text { men with BPD. } \\
\text { Mean age }=22.0 \text { yrs (range=18- } 27 \\
\text { yrs) }\end{array}$ & $\begin{array}{l}\text { Quality of therapeutic } \\
\text { alliance }\end{array}$ & $\begin{array}{l}\text { DBT group improved more } \\
\text { than controls on most } \\
\text { outcomes }\end{array}$ \\
\hline $\begin{array}{l}\text { Wenzel et } \\
\text { al. }\end{array}$ & 2006 & USA & СBT & No & $n=32$ & $\begin{array}{l}28 \text { women and } 4 \text { men with BPD. } \\
\text { Mean age }=29.0 \text { yrs (range }=20-55 \\
\text { yrs) [from Brown et al., 2004] }\end{array}$ & $\begin{array}{l}\text { Belief change, } \\
\text { reduction in } \\
\text { hopelessness, } \\
\text { improvement in } \\
\text { attitude towards } \\
\text { treatment }\end{array}$ & $\begin{array}{l}\text { Positivity towards treatment } \\
\text { correlated with improvement } \\
\text { in BPD diagnostic criteria }\end{array}$ \\
\hline
\end{tabular}


Table 2: $\quad$ Checklist appraisal of DBT studies according to the DBC (Downs \& Black,1998)

\begin{tabular}{|c|c|c|c|}
\hline Paper & Strengths according to DBC & Limitations according to DBC & $\begin{array}{l}\text { Total DBC score } \\
(/ 28)\end{array}$ \\
\hline Axelrod et al. (2011) & Reporting, sampling & $\begin{array}{l}\text { Attrition ( } 44.4 \% \text { did not complete } \\
\text { treatment), small sample, lack of control } \\
\text { group }\end{array}$ & 16 \\
\hline Barnicot et al. (2015) & $\begin{array}{l}\text { Reporting, outcome measure, statistical } \\
\text { techniques }\end{array}$ & $\begin{array}{l}\text { Attrition ( } 46 \% \text { did not complete treatment), } \\
\text { lack of control group }\end{array}$ & 21 \\
\hline Bedics et al. (2015) & $\begin{array}{l}\text { Randomisation, control group, large } \\
\text { sample }\end{array}$ & $\begin{array}{l}\text { Reliance on self-report and lack of control } \\
\text { of confounding variables }\end{array}$ & 21 \\
\hline Bedics et al. (2012) & $\begin{array}{l}\text { Randomisation, control group, large } \\
\text { sample }\end{array}$ & $\begin{array}{l}\text { Reliance on self-report, unable to } \\
\text { determine treatment compliance }\end{array}$ & 21 \\
\hline Kramer et al. (2016) & $\begin{array}{l}\text { Randomisation, blinding of observers, } \\
\text { control group }\end{array}$ & Non-blinding of participants & 25 \\
\hline Linehan et al. (2015) & $\begin{array}{l}\text { Randomisation, comparison groups, blind } \\
\text { assessors, participant matching }\end{array}$ & Non-blinding of participants & 24 \\
\hline McMain et al. (2013) & $\begin{array}{l}\text { Randomisation, statistical control of data, } \\
\text { control of confounds, control group }\end{array}$ & $\begin{array}{l}\text { Non-blinding of participants and } \\
\text { researchers }\end{array}$ & 25 \\
\hline Neacsiu et al. (2010) & $\begin{array}{l}\text { Randomisation, control group, blind } \\
\text { assessors }\end{array}$ & Non-blinding of participants & 26 \\
\hline O'Toole et al. (2012) & $\begin{array}{l}\text { Reporting, sampling, large sample size, } \\
\text { analyses }\end{array}$ & $\begin{array}{l}\text { Lack of control group, presence of } \\
\text { confounding variables }\end{array}$ & 18 \\
\hline Perroud et al. (2012) & Outcome measures, sampling & Lack of control group & 19 \\
\hline Turner (2000) & $\begin{array}{l}\text { Randomisation, blind, independent } \\
\text { assessors }\end{array}$ & Lack of information about non-completers & 21 \\
\hline Stepp et al. (2008) & Reporting, statistical analyses & $\begin{array}{l}\text { Non-randomisation, lack of control group, } \\
\text { small sample size }\end{array}$ & 15 \\
\hline
\end{tabular}




\begin{tabular}{lll}
\hline \multicolumn{1}{c}{ Paper } & Strengths according to DBC & Limitations according to DBC \\
\hline Gibbons et al. (2009) & $\begin{array}{l}\text { Randomisation, large sample, } \\
\text { control/comparison groups }\end{array}$ & Non-blinding of participants \\
Wenzel et al. (2006) & $\begin{array}{l}\text { Management of data from participants lost } \\
\text { to follow-up }\end{array}$ & Lack of control group \\
\hline
\end{tabular}

